\title{
Immunoglobulins to mitigate paraneoplastic Lambert Eaton Myasthenic Syndrome under checkpoint inhibition in Merkel cell carcinoma
}

\author{
Maike F. Dohrn ${ }^{1,2^{*}}$ D, Ulrike Schöne ${ }^{1}$, Charlotte Küppers ${ }^{1}$, Deborah Christen ${ }^{3}$, Jörg B. Schulz ${ }^{1}$, Burkhard Gess ${ }^{1}$ \\ and Simone Tauber ${ }^{1}$
}

\begin{abstract}
Lambert-Eaton myasthenic syndrome (LEMS) is a rare, autoimmune or paraneoplastic condition characterized by muscle weakness and fatigability. In cancer therapy, immune checkpoint inhibitors (ICI) sensitize the immune system for tumor antigens.

We report a 62-year-old, female patient with paraneoplastic LEMS as first manifestation of Merkel cell carcinoma. Under avelumab, the LEMS exacerbated with worsening of limb weakness and a severely reduced vital capacity $(<1$ I). To treat this immunological side effect, we added a regimen with intravenous immunoglobulins. Hereby, the LEMS improved significantly. As we were able to continue the cancer treatment, the Merkel cell carcinoma has been in remission so far.

This is the first description of paraneoplastic LEMS, avelumab, and Merkel cell carcinoma. We conclude that immunoglobulins are an option to control an $\mathrm{ICl}$-associated deterioration of paraneoplastic symptoms.
\end{abstract}

\section{Case}

A 62-year-old female patient presented with bilateral ptosis, dysphagia, and combined distal and proximal muscle weakness and fatigability. The clinical examination revealed a positive Simpson-test, hand muscle weakness, and an impaired proximal endurance. The 3 Hz-repetitive stimulation showed a significant decrement of compound muscle action potentials (CMAP) of the left trapezius and both anconeus muscles. PQ-type VGCC antibodies were elevated in serum by $387.6 \mathrm{pmol} /$ $1(<40)$, while antibodies against the acetylcholine receptor were negative. We began a symptomatic treatment of

\footnotetext{
*Correspondence: mdohrn@ukaachen.de; mfd83@miami.edu

'Department of Neurology, Medical Faculty of the RWTH Aachen University, Aachen, Germany

${ }^{2}$ Dr. John T. Macdonald Foundation, Department of Human Genetics and John P. Hussman Institute for Human Genomics, University of Miami, Miller School of Medicine, Miami, Florida, USA

Full list of author information is available at the end of the article
}

the Lambert-Eaton myasthenic syndrome (LEMS) with 3,4-diaminopyridine and pyridostigmine. As 50\% of LEMS cases arise in a paraneoplastic context [1], a PETCT revealed inguinal lymph nodes suspicious for malignancy. A biopsy disclosed lymphogenic metastases of Merkel cell carcinoma, the primary origin of which remained unknown. The patient received avelumab, a recently approved immune checkpoint inhibitor (ICI) [2], which led to tumor remission. To enhance the immune response, avelumab targets the programmed cell death ligand (PD-L1), which is known to be upregulated by tumor cells to escape the recognition of $\mathrm{T}$ cells. In this patient, ICI treatment led to a significant worsening of limb weakness requiring the use of a walker, and a severely reduced vital capacity $(<1 \mathrm{l})$. The risks of both receiving and withdrawing avelumab were addressed in an interdisciplinary oncological board and discussed with the patient. Considering the severity of the underlying malignancy, ICI treatment could not be halted for good.

(c) The Author(s). 2020 Open Access This article is licensed under a Creative Commons Attribution 4.0 International License, which permits use, sharing, adaptation, distribution and reproduction in any medium or format, as long as you give appropriate credit to the original author(s) and the source, provide a link to the Creative Commons licence, and indicate if changes were made. The images or other third party material in this article are included in the article's Creative Commons licence, unless indicated otherwise in a credit line to the material. If material is not included in the article's Creative Commons licence and your intended use is not permitted by statutory regulation or exceeds the permitted use, you will need to obtain permission directly from the copyright holder. To view a copy of this licence, visit http://creativecommons.org/licenses/by/4.0/.
} 
For the same reason, cell-depleting immunosuppressants such as rituximab were not our first choice of treatment, especially as the combination of such drugs with avelumab has never been examined. Plasmapheresis was discussed as an option, but not preferred considering that a longterm therapy was needed. As the patient already hat type 2 diabetes mellitus and osteoporosis, we aimed at avoiding a repetitive or long-term steroid treatment as well. An immediate intervention with intravenous immunoglobulins in a dosage of $2 \mathrm{~g} / \mathrm{kg}$ body weight over five consecutive days enabled a subjective improvement of symptoms. We continued the immunoglobulin treatment in an intermittent dosage of $1 \mathrm{~g} / \mathrm{kg}$ body weight every four weeks, which was well tolerated. The patient reported a dynamic worsening of symptoms in the last week before and a subjective improvement following immunoglobulin treatment. After six-months, an improvement in proximal strength enabled her to walk up to $500 \mathrm{~m}$. The endurance tests of both arms and legs had normalized. The distal muscle strength was still impaired, and the Simpson test remained positive. The vital capacity was $1.5 \mathrm{l}$, and the Besinger's score had declined from 6 to 4 points. The former decrement of the left trapezius muscle was no longer reproducible. Following tetanic stimulation, there was a significant CMAP increment of the abductor digiti minimi muscles on both sides (Fig. 1a, b). An anconeus muscle decrement became apparent in the $3 \mathrm{~Hz}$ repetitive stimulation of both radial nerves (Fig. 1c). The Merkel cell carcinoma has so far been in complete remission.

\section{Discussion}

Enabling the immune system to resist elaborate tumor escape strategies such as PD-L1 expression, the concept of immune checkpoint inhibition has won the Nobel prize in 2018. Antagonists against this or other ligands and receptors, however, can lead to the collateral offense of other targets including the pre-synaptic calcium channel VGCC that structurally resembles certain tumor antigens $[3,4]$. A paraneoplastic LEMS can precede the tumor diagnosis by several years [1]. There are no trial-based data on using ICI drugs in cases of pre-existing paraneoplastic syndromes [5], especially if the tumor stage prevents other alternatives.

This patient is the first case receiving avelumab despite having a paraneoplastic LEMS. Other authors described four patients with avelumab-treated thymoma developing myositis [6] and another patient with small lung cell carcinoma developing LEMS while being treated with nivolumab [7].

With the patient's yet metastasized malignancy on the one and the potentially life-threatening LEMS on the other hand, we had to outweigh the respective risks and chose to add intravenous immunoglobulins to the previous ICI treatment. In the six-months observation interval, the patient thereby improved significantly. We conclude that immunoglobulins are a conceivable treatment option to control an ICI-associated deterioration of paraneoplastic symptoms.
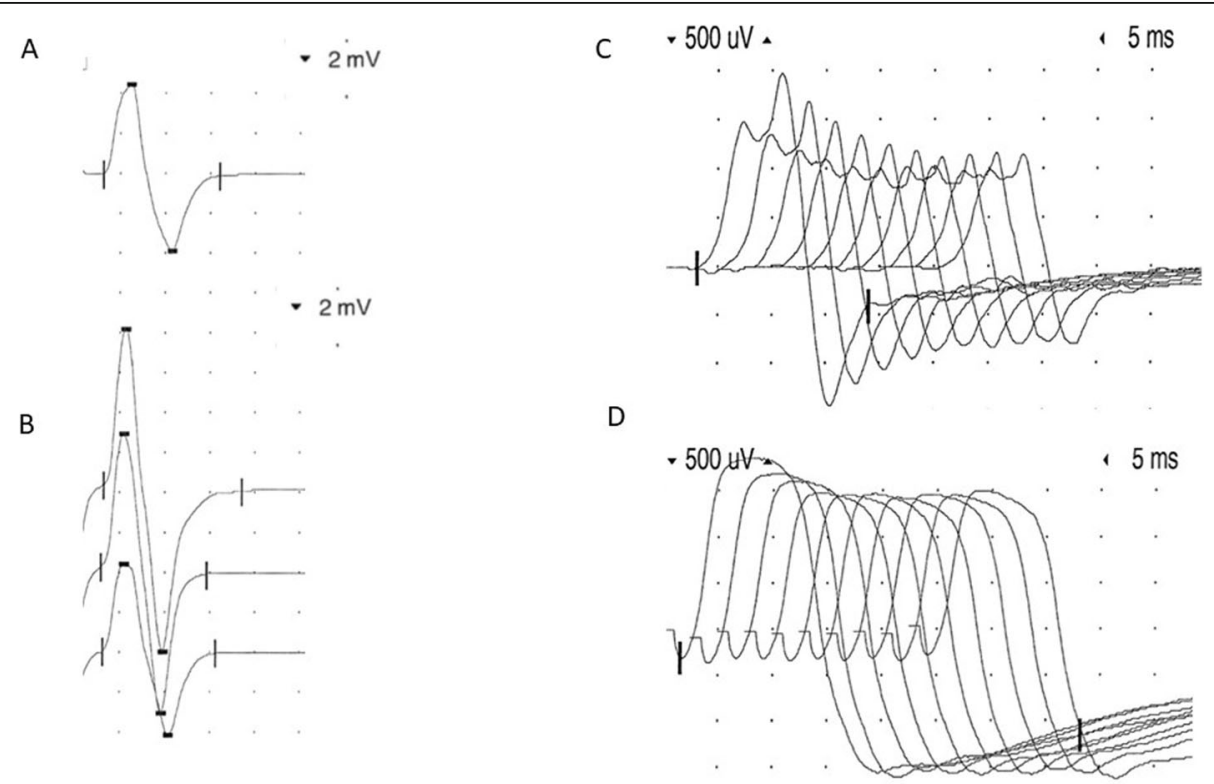

Fig. 1 Neurophysiological examinations. a Compound muscle action potential (CMAP) of the left abductor digiti minimi muscle (8.4 mV). b Significant increment $(16.2 \mathrm{mV}$ ) following tetanic stimulation. c $43 \%$ decrement under $3 \mathrm{~Hz}$ repetitive stimulation of the left anconeus muscle. $\mathbf{d}$ $19 \%$ decrement of the right trapezius muscle (at first visit only) 


\section{Abbreviations}

CMAP: Compound muscle action potential; ICl: Immune checkpoint inhibition; LEMS: Lambert Eaton Myasthenic Syndrome; PD-L1: Programmed cell death ligand 1; VGCC: Voltage-gated calcium channel

\section{Authors' contributions}

MFD: acquisition of data, analysis and interpretation of data, drafting of the manuscript. US: acquisition of data, critical review of the manuscript; CK: acquisition of data, critical review of the manuscript; DC: acquisition of data, critical review of the manuscript; JBS study supervision, critical review of the manuscript; BG: analysis and interpretation of data, study supervision, critical review of the manuscript; ST: analysis and interpretation of data, study supervision, critical review of the manuscript. The author(s) read and approved the final manuscript.

\section{Funding}

There was no funding of this case-report.

\section{Availability of data and materials}

Not applicable.

\section{Consent for publication}

We obtained the patient's written consent for publication.

\section{Competing interests}

Maike F. Dohrn has received scientific funding from Pfizer (ASPIRE 2018), has served as a paid consultant for Amicus, Akcea, Alnylam, and Pfizer, and is currently receiving a scholarship for a research fellowship by the German Research Foundation (Deutsche Forschungsgemeinschaft, DFG). Jörg B. Schulz serves at advisory boards for Biogen and Roche. Burkhard Gess received financial support from Pfizer, Grifols, and Bayer for conference contributions. Simone Tauber has participated in paid scientific advisory boards by Roche and received financial travelling support and consultant honoraries by Novartis, Tena, Merck, Roche, and Biogen. All of the aforementioned conflicts are not related to the content of the manuscript. US, CK, and DC have no conflicts to disclose. All authors read and approved the manuscript.

\section{Author details}

'Department of Neurology, Medical Faculty of the RWTH Aachen University, Aachen, Germany. ${ }^{2}$ Dr. John T. Macdonald Foundation, Department of Human Genetics and John P. Hussman Institute for Human Genomics, University of Miami, Miller School of Medicine, Miami, Florida, USA. ${ }^{3}$ Department of Oncology and Hematology, Medical Faculty of the RWTH Aachen University, Aachen, Germany.

Received: 3 November 2020 Accepted: 30 November 2020

Published online: 09 December 2020

\section{References}

1. Guidon, A. (2019). Lambert-Eaton Myasthenic Syndrome, Botulism, and Immune Checkpoint Inhibitor-Related Myasthenia Gravis. Continuum (Minneap Minn), 25, 1785.

2. Kaufman, H. L., Russell, J., Hamid, O., et al. (2016). Avelumab in patients with chemotherapy-refractory metastatic Merkel cell carcinoma: A multicentre, single-group, open-label, phase 2 trial. The Lancet Oncology, 17, 1374-1385

3. Graus, F., \& Dalmau, J. (2019). Paraneoplastic neurological syndromes in the era of immune-checkpoint inhibitors. Nature Reviews Clinical Oncology, 16(9): 535-548. https://doi.org/10.1038/s41571-019-0194-4

4. Zekeridou, A., \& Lennon, V. A. (2019). Neurologic autoimmunity in the era of checkpoint inhibitor cancer immunotherapy. Mayo Clinic proceedings, 94(9): 1865-1878. https://doi.org/10.1016/j.mayocp.2019.02.003.

5. Brahmer, J. R., Lacchetti, C., Schneider, B. J., et al. (2018). Management of immune-related adverse events in patients treated with immune checkpoint inhibitor therapy: American Society of Clinical Oncology clinical practice guideline. Journal Clinic of Oncology, 36, 1714.

6. Mammen, A. L., Rajan, A., Pak, K., et al. (2019). Pre-existing antiacetylcholine receptor autoantibodies and $B$ cell lymphopaenia are associated with the development of myositis in patients with thymoma treated with avelumab, an immune checkpoint inhibitor targeting programmed death-ligand 1 . Annals of the rheumatic diseases, 78, 150-152.
7. Nakatani, Y., Tanaka, N., Enami, T., Minami, S., Okazaki, T., \& Komuta, K. (2018), Lambert-Eaton Myasthenic Syndrome caused by Nivolumab in a patient with squamous cell lung Cancer. Case Reports Neurology, 10, 346.

\section{Publisher's Note}

Springer Nature remains neutral with regard to jurisdictional claims in published maps and institutional affiliations.
Ready to submit your research? Choose BMC and benefit from:

- fast, convenient online submission

- thorough peer review by experienced researchers in your field

- rapid publication on acceptance

- support for research data, including large and complex data types

- gold Open Access which fosters wider collaboration and increased citations

- maximum visibility for your research: over $100 \mathrm{M}$ website views per year

At BMC, research is always in progress.

Learn more biomedcentral.com/submissions 